\title{
Spacing and the retention of synonyms
}

\author{
LEONARD D. STERN and DOUGLAS L. HINTZMAN \\ University of Oregon, Eugene, Oregon 97403
}

\begin{abstract}
Two experiments investigated the retention of word pairs as a joint function of synonymity and of Word 1/Word 2 spacings. Word 1 and Word 2 were adjectives or adverbs, presented in identical sentence contexts, for either intentional (Experiment 1) or incidental (Experiment 2) learning. In both experiments, it was found that as the spacing between the first and second members of the high-similarity pairs increased, recognition of the word pairs decreased (i.e., a reverse spacing effect). For low-similarity pairs, only incidental learning instructions led to a reverse spacing effect. A positive, rather than reverse, spacing effect had been predicted for high-similarity word pairs. Implications of the unexpected finding are discussed.
\end{abstract}

If an item is presented more than once in a list, retention of the item will increase as the interval between presentations increases from 0 to $15 \mathrm{sec}$. This phenomenon, known as the spacing effect (Hintzman, 1974), has been found using a wide variety of stimuli and memory tasks. But in spite of its resilience, the spacing effect can be quite sensitive to certain similarity manipulations. If the second presentation of a stimulus $\left(\mathrm{P}_{2}\right)$ is not identical to the first presentation $\left(\mathrm{P}_{1}\right)$, the usual spacing effect may not occur. For example, Glanzer and Duarte (1971) obtained an attenuated spacing effect when $P_{1}$ and $P_{2}$ were the same word presented in two languages. Similarly, Hintzman and Stern (1977) found a greatly attenuated spacing effect with pictures when $\mathrm{P}_{2}$ was the mirror-image reversal of $P_{1}$. Attempts to bias the meaning of homographs by using different context words have been found to lead to either flat spacing curves (Gartman \& Johnson, 1972), or small reverse spacing effects (Hintzman, Summers, \& Block, 1975). In the reverse spacing effect, massed items are remembered better than spaced items. Finally, when $P_{1}$ and $\mathrm{P}_{2}$ are related words (e.g., king, queen), a reverse spacing effect generally results (Glanzer, 1969; Hintzman et al., 1975).

It appears that the different effects of spacing arise from manipulations of the semantic rather than the "surface" properties of $P_{1}$ and $P_{2}$. Hintzman, Block, and Summers (1973) and Wells and Kirsner (1974) found that manipulating a surface property, the presentation modality of words, does not attenuate the spacing effect. Taken together, these studies suggest that a normal spacing effect is obtained when $\mathrm{P}_{1}$ and $\mathrm{P}_{2}$ are semantically equivalent, whereas a reverse spacing effect results when $P_{1}$ and $P_{2}$ are related but semantically different. Attenuated spacing curves obtained with translated words

This paper is based on a master's thesis by the first author submitted to the graduate school of the University of Oregon. The study was funded in part by BRSG Grant RR-07080 awarded by the Biomedical Research Support Grant Program, Division of Research Resources, National Institutes of Health. and reversed pictures presumably represent a point intermediate between the two extremes.

To test this possibility, we varied the Word 1/Word 2 spacing of matched pairs of adjectives or adverbs that were identical, highly synonymous, somewhat synonymous, or semantically unrelated. To further constrain word meanings, both members of a matched pair were presented in identical sentence contexts. Retention of the matched words was tested using both cued recall and recognition procedures. It was expected that the identical word pairs would lead to a positive spacing effect, highly synonymous pairs to an attenuated positive spacing effect, and low-synonym pairs to a flat or an attenuated reverse spacing curve. Because the members of unrelated word pairs were semantically dissimilar but related by virtue of being presented in an identical context, it was anticipated that these items would produce a strong reverse spacing curve.

\section{Generation of Materials}

For each of 67 adjectives and adverbs (termed key words), the experimenter chose a high-similarity $(\mathrm{H})$ and a low-similarity (L) match. An appropriate sentence frame was generated for each key word, which was underlined and inserted in the frame (e.g., Jane's costume was unusual). The same sentence frame was used for each key word and its two matches.

Two lists were prepared using these sentences. One list contained all $67 \mathrm{key}$ words, each followed by either its $\mathrm{H}$ or its $\mathrm{L}$ match, randomly selected. The other match was then assigned to the key word in a similar manner, in the second list. Order of presentation was of interest, so from each of the two lists another list was prepared in which the order of presentation of the matched sentence pairs was reversed.

Each of 75 subjects saw one of the four lists and rated the underlined words of each sentence pair for similarity of meaning. Judgments were given on a scale of 1 to 5 , with 1 indicating exactly the same meaning and 5 indicating very different meanings.

The 67 key word-H and key word-L match ratings 
Table 1

Examples of Sentence Frames and Their Synonym Sets

\begin{tabular}{|c|c|c|c|}
\hline \multirow[b]{2}{*}{ Sentence Frame } & \multirow[b]{2}{*}{ Key Word } & \multicolumn{2}{|c|}{ Synonym Similarity } \\
\hline & & High & Low \\
\hline $\begin{array}{l}\text { The guide pointed to the } \\
\text { Jane's costume was } \\
\text { The climbers maintained a } \\
\text { The hotel manager's manner was pace. }\end{array}$ & $\begin{array}{l}\text { distant } \\
\text { unusual } \\
\text { leisurely } \\
\text { courteous }\end{array}$ & $\begin{array}{l}\text { faraway } \\
\text { odd } \\
\text { unhurried } \\
\text { polite }\end{array}$ & $\begin{array}{l}\text { inaccessible } \\
\text { grotesque } \\
\text { deliberate } \\
\text { suave }\end{array}$ \\
\hline
\end{tabular}

were then compared in 67 ANOVAs. Of the 67 synonym sets, the 24 producing the largest $F$ ratios were then selected as experimental materials. The mean ratings for these 24 key word-H and key word-L matches were 1.76 and 3.60 , with standard deviations of .35 and .48 , respectively. Table 1 shows examples of sentence frames, together with $\mathrm{H}$ and $\mathrm{L}$ matches for four key words.

\section{EXPERIMENT 1}

\section{Method}

Materials. The stimuli were 124 sentences, each containing an underlined adjective or adverb. Sentences were either unique (henceforth termed single-presentation, or S, items) or paired. Paired sentences were identical except for the underlined words, which were related in one of the following ways: They were identical (I), synonymous-high (H), synonymous-low (L), or unrelated $(U)$ in meaning. The 24 sentences selected as just described served as $\mathrm{H}$ and $\mathrm{L}$ stimuli; sentence pairs for the $\mathrm{U}$ condition were prepared by inserting each member of a pair of unrelated words in an appropriate sentence frame (e.g., The corner lot was level; The corner lot was empty).

A set of 124 slides of experimental sentences was prepared from transparencies that had originally been typed on paper and reduced in size by a Xerox process. Three blocks of these slides, each containing four pairs of $\mathrm{I}, \mathrm{H}, \mathrm{L}$, and $\mathrm{U}$ sentences and four $S$ sentences, were arranged in a random order in two slide trays. In each slide block, one of the four sentence pairs of each type was assigned to each of four $P_{1}-P_{2}$ spacings: Sentence pairs were separated by zero, one, three, or five slides. Sixteen filler sentences occupied the first six and the last six positions, as well as four other positions within the list.

The cued recall test form consisted of 72 randomly ordered sentence frames, each containing a blank space where a word was missing. Sixty of the sentence frames had been used for the $\mathrm{S}, \mathrm{I}, \mathrm{H}, \mathrm{L}$, and $\mathrm{U}$ items in the experimental list; the words that had been underlined in that list were missing. The remaining 12 sentence frames were new.

The recognition test form contained 144 adjectives and adverbs; 96 of these were the underlined words from the experimental list and 48 were distractors. These distractors included 12 words that were highly synonymous to "old" words on the list, and 12 that were low-similarity matches of "old" words.

There were 16 rotations of experimental items, permitting each $I, H, L$, and $U$ pair to serve in each spacing condition and enabling $P_{:}-P_{2}$ assignments of the $H, L$, and $U$ pair members to be interchanged. Switching of $\mathrm{L}$ and $\mathrm{H}$ items was also conducted, so that each key word was paired with its $\mathrm{H}$ match half the time and with its $L$ match half the time. $S$ and I sentences were also interchanged.

Procedure. Subjects were given intentional learning instructions that stressed the need to attend not only to the underlined word in each sentence, but also to the sentence frame. The form of the memory test was not specified.
A slide projector displayed each experimental slide for $5 \mathrm{sec}$. When all the slides had been shown, subjects were given the cued recall test form. Subjects were instructed to write the appropriate word or pair of words into each sentence frame that they remembered being shown in the experimental list. New sentence frames were to be left blank. No time limit was imposed for the cued recall test or for the recognition test that followed. Instructions on the top of the recognition test forms directed subjects to circle those words on the form that they recognized as being underlined words from the experimental list.

Subjects. Ninety-eight paid subjects, recruited from the University of Oregon community, were tested in groups of two to eight persons each. The data of two subjects were discarded for failure to follow instructions.

Analyses. For both tests, a response given to $\mathrm{H}, \mathrm{L}$, or $\mathrm{U}$ pairs at each spacing interval was counted as correct if either $P_{1}$ or $P_{2}$ was correct, or if both were correct. Performance was also determined for $P_{1}$ and $P_{2}$ individually. For zero-frequency items (i.e., sentence frames or underlined words that appeared only on the test forms), a response was counted as correct if the sentence frame was left blank (cued recall test) or if the word was not circled (recognition test).

\section{Results}

Effects of spacing were tested by means of planned comparisons, using the coefficients $-5,1,2$, and 2 . For the cued recall test, spacing had a significant effect on retention only for the I condition $[F(1,95)=31.8$, $\mathrm{p}<.001$ ] . F values were less than 1 for the $U, L$, and $\mathrm{H}$ conditions.

When memory was tested by recognition (Figure 1), spacing had a significant effect, although in opposite directions for the I condition $[\mathrm{F}(1,95)=18.8, \mathrm{p}<.001]$ and the $\mathrm{H}$ condition $[\mathrm{F}(1,95)=5.04, \mathrm{p}<.05]$. Spacing was only marginally significant in the $U$ condition

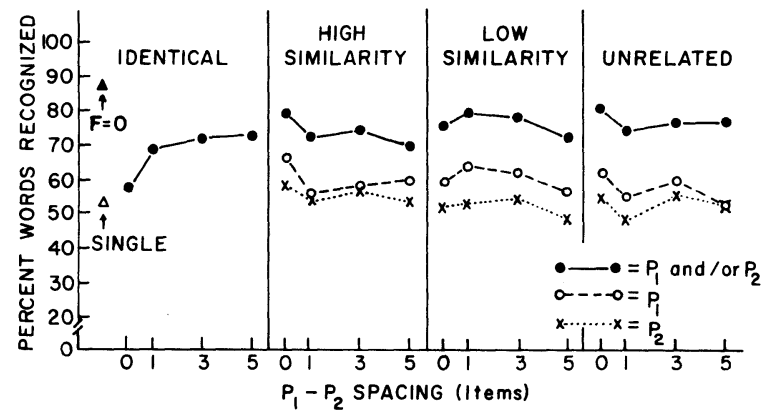

Figure 1. Recognition test data from Experiment 1 (intentional learning instructions): Percent words correctly recognized as a function of spacing. 
$[F(1,95)=2.9, p<.10]$ and had no reliable effect in the $L$ condition $(F<1)$.

For the individual $P_{1}$ and $P_{2}$ values on the cued recall test, neither $\mathrm{P}_{1}$ nor $\mathrm{P}_{2}$ recall was affected by spacing (all $F s<1$ ). For the recognition test, however, $\mathrm{P}_{1}$ of the $\mathrm{H}$ and $\mathrm{U}$ conditions showed significant reverse spacing effects $[\mathrm{F}(1,95)=6.2, \mathrm{p}<.025$, and $\mathrm{F}(1,95)=$ $5.0, \mathrm{p}<.05$, respectively]. Collapsed over spacings, $P_{1}$ of the $U, L$, and $H$ conditions was better remembered than $\mathrm{P}_{2}$ on both the cued recall test and the recognition test (all ps $<.025$ ). Retention of $P_{1}$ collapsed over spacings in the $\mathrm{H}, \mathrm{L}$, and $\mathrm{U}$ conditions combined was significantly better than that of $\mathrm{S}$ items for both the recognition and cued recall tests $[\mathrm{F}(1,95)=25.38$, $\mathrm{p}<.001$, and $\mathrm{F}(1,95)=40.80, \mathrm{p}<.001$, respectively] .

\section{EXPERIMENT 2}

A reverse spacing effect for the $\mathrm{H}$ condition of Experiment 1 was unexpected, since it was assumed that the semantic encodings of these sentence pairs would be virtually identical. Subjects may, however, have had a tendency to retrieve the trace of $P_{1}$ when given $\mathrm{P}_{2}$ and to search for and emphasize differences between the meanings of the underlined words. To eliminate such a deliberate strategy, subjects in Experiment 2 were given incidental learning instructions. The materials were identical to those of Experiment 1; however, only a recognition test was given.

\section{Method}

Materials and Procedure. The stimuli were identical to those of Experiment 1. However, subjects were not instructed to learn, but rather to form an image of the scene or situation described in each sentence and to rate, on a scale of 1 to 4 , how difficult each image was to construct. Slides were shown at a 6-sec rate, and then subjects were tested with the same recognition test form used in Experiment 1.

Subjects. Eighty-eight paid subjects were recruited and tested as in Experiment 1; none of the subjects had participated in the previous experiment.

\section{Results}

Figure 2 shows the data. Again, as in Experiment 1, the effect of spacing on retention was significant in the I condition $[F(1,87)=7.92, p<.01]$. Significant reverse spacing effects occurred for both the $\mathrm{L}$ and $\mathrm{H}$ conditions $[F(1,87)=5.24, p<.025$, and $F(1,87)=$ $11.26, \mathrm{p}<.01$, respectively]. Spacing had no reliable effect in the $U$ condition $(F<1)$.

Recognition of $\mathrm{P}_{1}$ and $\mathrm{P}_{2}$ were both affected by spacing in the $H$ condition $[F(1,87)=5.25, p<.025$, and $F(1,87)=7.25, p<.01$, respectively]. In the $L$ condition, only $\mathrm{P}_{2}$ showed effects of spacing that approached significance $[F(1,87)=3.13, p<.10]$.

Collapsed over spacings, $\mathrm{P}_{2}$ was retained better than $\mathrm{P}_{1}$ for the $\mathrm{U}, \mathrm{L}$, and $\mathrm{H}$ conditions combined $[\mathrm{F}(1,87)=$ $20.65, p<.001]$. These data suggest that $P_{1}$ had some

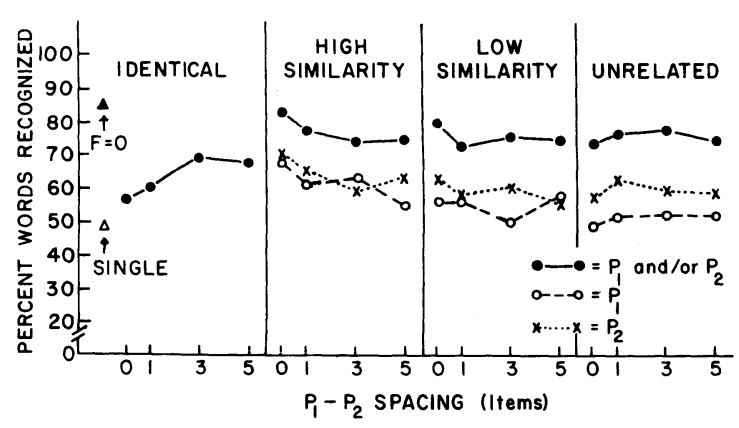

Figure 2. Recognition test data from Experiment 2 (incidental learning instructions): Percent words correctly recognized as a function of spacing.

facilitating effect on memory for $\mathrm{P}_{\mathbf{2}}$. Statistical tests confirmed this by showing that performance on $\mathrm{P}_{2}$ of the $U, L$, and $H$ conditions combined was significantly better than that on $S$ items $[F(1,87)=14.87$, $\mathrm{p}<.001]$. Performance on $\mathrm{P}_{1}$ of the $\mathrm{U}, \mathrm{L}$, and $\mathrm{H}$ conditions combined did not differ significantly from that on $\mathrm{S}$ items. Very different results occurred in Experiment 1, due, perhaps, to subjects' use of the strategy of retrieving and rehearsing $\mathrm{P}_{1}$ during $\mathrm{P}_{2}$. An analysis of the recognition data from Experiment 1 revealed that it was $P_{1}$ of the $U, L$, and $H$ conditions combined that was remembered significantly better than $\mathrm{S}$ items $[\mathrm{F}(1,95)=25.38, \mathrm{p}<.001]$.

\section{GENERAL DISCUSSION}

Contrary to predictions, the use of highly synonymous word pairs led to reverse rather than positive spacing curves. This occurred even though the meanings were constrained by the sentence frames to be virtually identical. This finding does not support the view that there is a continuous transition from positive to reverse spacing curves as the semantic overlap between $P_{1}$ and $P_{2}$ decreases.

The data from these experiments are consistent with the view that a trace-enrichment process underlies the reverse spacing effect. It appears that if two words have some conspicuous preexperimental relation to each other (e.g., they are both of the same conceptual category) and also have features that are not shared, the amount of information stored about them will be enhanced when they are presented successively. The enhanced information, presumably, consists of those elements or features that the two words do not hold in common.

Why is it that Glanzer and Duarte (1971) found a normal spacing curve using English-Spanish translations, while the present study, using highly synonymous adjectives and adverbs, found a reverse spacing curve? Perhaps, in accordance with an independent storage hypothesis (Liepmann \& Saegert, 1974), bilingual subjects represent words in a supralinguistic code, one that is based on meaning and is independent of the language in which the words are presented. Synonyms, on the other hand, may never have identical representations (Herrmann, 1978), even when their meanings are carefully matched and controlled. According to a trace-elaboration account of the reverse spacing effect, then, it is this incomplete semantic overlap of synonym pairs that allowed us to obtain reverse spacing curves. 


\section{REFERENCES}

Gartman, L. M., \& Johnson, M. F. Massed versus distributed repetitions of homographs: A test of the differential-encoding hypothesis. Journal of Verbal Learning and Verbal Behavior, 1972, 11, 801-808.

Glanzer. M. Distance between related words in free recall: Trace of the STS. Journal of Verbal Learning and Verbal Behavior, $1969,8,105-111$.

Glanzer, M., \& Duarte, A. Repetition between and within languages in free recall. Journal of Verbal Learning and Verbal Behavior, 1971, 10, 625-630.

HerrmanN, D. J. An old problem for the new psychosemantics: Synonymity. Psychological Bulletin, 1978, 85, 490-512.

Hintzman, D. L. Theoretical implications of the spacing effect. In R. L. Solso (Ed.), Theories in cognitive psychology: The Loyola symposium. Potomac, Md: Erlbaum, 1974.

Hintzman, D. L., Block, R. A., \& Summers, J. J. Modality tags and memory for repetitions: Locus of the spacing effect. Journal of Verbal Learning and Verbal Behavior, 1973, 12, 229-238.

Hintzman, D. L., \& Stern, L. D. Spacing, mirror-image repetition, and memory for pictures. Bulletin of the Psychonomic Society, 1977, 10, 321-324.

Hintzman, D. L., Summers, J. J., \& Block, R. A. Spacing judgments as an index of study-phase retrieval. Journal of Experimental Psychology: Human Learning and Memory, 1975, 1, 31-40.

Liepmann, D., \& SaEgert, J. Language tagging in bilingual free recall. Journal of Experimental Psychology, 1974, 103, 1137-1141.

Wells, J. E., \& Kirsner, K. Repetition between and within modalities in free recall. Bulletin of the Psychonomic Society, 1974, 2, 395-397.

(Received for publication February 23, 1979.) 